\title{
Water-borne Fluoride and Cortical Bone Mass: A Comparison of Two Communities
}

\author{
K.R. PHIPPS ${ }^{1}$ and B.A. BURT \\ School of Public Health, University of Michigan, Ann Arbor, Michigan 48109-2029
}

This study investigated the relationship between cortical bone mass in an older female population and their ingestion of fluoride from community water supplies. The study was conducted among lifelong female residents in Lordsburg $(3.5 \mathrm{ppm}$ fluoride) and Deming (0.7 ppm fluoride), NM. A total of 151 postmenopausal women ranging in age from 39 to 87 years took part; 69 were residents of the optimal-fluoride community, while the remaining 82 were residents of the high-fluoride community. Although bivariate analyses showed no difference in cortical bone mass between women in the two communities, with multiple regression analyses, significant predictors of bone mass $(p<0.05)$ were weight, years since menopause, current estrogen supplementation, diabetes, and fluoride exposure status. Based on a model containing all of these variables, women living in the high-fluoride community had a bone mass ranging from 0.004 to $0.039 \mathrm{~g} / \mathrm{cm}^{2}$ less than that of similar women living in the optimum-fluoride community. These results suggest that lifelong ingestion of water containing $3.5 \mathrm{ppm}$ fluoride, compared with water containing $0.7 \mathrm{ppm}$ fluoride, does not increase cortical bone mass in women of similar age, weight, and menopausal status. Under the conditions of this study, cortical bone mass might be reduced in a high-fluoride area.

\section{J Dent Res 69(6):1256-1260, June, 1990}

\section{Introduction.}

Since the addition of fluoride to drinking waters first began in 1945 , the nature of its influence on human bone has been debated. Leone et al. (1955), in a ten-year radiographic study, reported no detrimental effects on bone for individuals ingesting water containing 8.0 parts per million (ppm) of fluoride. The authors concluded that: "There is some indication that the ingestion of excessive fluoride in water and the 'fluoride effect' of the degree encountered in this study may, on occasion, have a beneficial effect on adult bone, as in counteracting the osteoporotic changes of the aged." Despite several flaws in the design and analysis of this study, the reported beneficial relationship between high-fluoride water and bone quality has been used for promotion of the fluoridation of water supplies.

A decreased calcification or density of bone is known as osteopenia. Because osteopenia is a descriptive term applicable to all skeletal systems, it carries no implication about causality. Since the 1955 report of Leone et al., several studies have been conducted in an attempt at clarification of the relationship between water-borne fluoride and skeletal osteopenia (Bern-

Received for publication May 29, 1989

Accepted for publication January 15, 1990

This study was supported by NIDR Grants RO3-DE 80534 and T32DE 07157.

${ }^{1}$ Currently with the Oregon Health Sciences University, School of Dentistry, 611 SW Campus Drive, Portland, Oregon 97201

Based on a dissertation submitted to the graduate faculty, University of Michigan School of Public Health, in partial fulfillment of the requirements for the $\mathrm{DrPH}$ degree stein et al., 1966; Ansell and Lawrence, 1966; Goggin et al., 1965; Madans et al., 1983; Simonen et al., 1984; Simonen and Laitinen, 1985; Arnala et al., 1986; Sowers et al., 1986; Lian and Wu, 1986; Avorn and Niessen, 1986). Because measurement of the mass of the entire skeletal system is difficult, the majority of these studies have used either hip-fracture incidence or bone mass at a specific site as a surrogate measure of osteopenia. Conflicting results, in some cases related to nonstandardized or even inadequate study methodologies, make the interpretation of existing data difficult. The goal of this study was to use a retrospective longitudinal study design to help clarify the relationship between the ingestion of fluoride via community water supplies and cortical bone mass in an older female population.

\section{Materials and methods.}

This study was based on a comparison of population groups in two culturally and economically similar communities in southwest New Mexico, Lordsburg and Deming (Table 1). The community water supply in Lordsburg contains fluoride at 4.2 parts per million (ppm F); records show that it has been consistently 3.5 ppm F or higher since at least 1933 (Dean, 1933; Striffler, 1955). Deming city water contains 0.7 ppm F, considered optimal for dental decay protection in this climatic region; records indicate that this fluoride level has also been stable throughout the years (US Public Health Service, 1959, 1969).

Lifelong female residents in each community were eligible for inclusion in the study if they met the following criteria: were post-menopausal (naturally or by an oophorectomy), were not immobilized, and had a lifelong history of ingesting city water. Study participants were recruited by local coordinators who were themselves lifelong residents and thus knew their communities well.

For this study, bone mass of the distal radius (75\% cortical bone) was utilized as the measure of cortical bone osteopenia. Because this measurement site can be accurately re-identified, the distal radius was chosen over other measurement sites, such as the mid-radius, so that longitudinal data could potentially be collected. Bone mass was measured via single-photon absorptiometry (Model 2780 Single Photon Bone Densitometer, Norland Corporation, Madison, WI, Fig.). This technique utilizes a highly collimated beam of mono-energetic radiation from an ${ }^{125}$ I source. The bone mineral content is assumed to be directly proportional to the amount of photon energy absorbed by the bone being studied (Andresen and Nielsen, 1986). In order for a physiological measure of bone mineral (bone mass) to be obtained, the software package connected to the absorptiometer divides the measured bone mineral content by the bone width. Throughout the study, Norland's protocol was followed-with the exception of calibration. To ensure that the equipment was properly calibrated for all scans, we calibrated the absorptiometer using a bone phantom twice per day rather than once a week, as suggested by the manufacturer. This was a far more rigorous calibration protocol than that used for routine clinical use. 
TABLE 1

DEMOGRAPHIC CHARACTERISTICS OF LORDSBURG AND DEMING, NEW MEXICO

\begin{tabular}{|c|c|c|}
\hline Variable & Deming & Lordsburg \\
\hline $\begin{array}{l}\text { Total Population } \\
\text { Hispanic Origin (percent) } \\
\text { White (percent) } \\
\text { Other (percent) }\end{array}$ & $\begin{array}{c}9964 \\
4984(50 \%) \\
4687(47 \%) \\
293(3 \%)\end{array}$ & $\begin{array}{l}3195 \\
2105(66 \%) \\
1249(33 \%) \\
41(1 \%)\end{array}$ \\
\hline Primary Industries & $\begin{array}{l}\text { Retail Trade, Construc- } \\
\text { tion, Public Utilities }\end{array}$ & $\begin{array}{l}\text { Retail Trade, Construc- } \\
\text { tion, Mining (copper) }\end{array}$ \\
\hline $\begin{array}{l}\text { Houshold Income } \\
\text { All Races } \\
\text { Median } \\
\text { Mean } \\
\text { Hispanic Origin } \\
\text { Median } \\
\text { Mean }\end{array}$ & $\begin{array}{r}9639 \\
12,686 \\
\\
9226 \\
11,707\end{array}$ & $\begin{array}{r}9765 \\
12,769 \\
\\
10,000 \\
12,276\end{array}$ \\
\hline $\begin{array}{l}\text { Percent High School } \\
\text { Graduates }\end{array}$ & 54.6 & 46.2 \\
\hline
\end{tabular}

Source: US Department of Commerce (1980).

In order to have a constant soft-tissue thickness, the forearm of each participant was wrapped in a tissue-equivalent bag. Two consecutive linear scans were then completed at a point where the radius and ulna were $5.0 \mathrm{~mm}$ apart (plus or minus $0.3 \mathrm{~mm}$ ). The results of the two scans, expressed as $\mathrm{g} / \mathrm{cm}^{2}$, were averaged and used as the dependent variable for statistical analysis.

Each individual participating in the study was interviewed so that information about known confounding variables could be secured. The analytical covariables collected from each participant were age, race, years since menopause, current medication use, known medical disorders, parity, current calcium intake, lean body mass, lifelong smoking status, and present alcohol consumption; present and past physical activity status were intended as analytical covariables. All, except nutrient status and lean body mass, were collected via an intervieweradministered questionnaire, either in Spanish or English. Lean body mass was evaluated by measurement of weight, height, triceps skinfold, and mid-arm circumference. Calcium intake from food was determined by use of a quantitative food frequency format developed by the National Cancer Institute (NCI). A lap-top computer, along with software also developed by $\mathrm{NCI}$, were used for direct data entry of the food frequency questionnaire. Using an NCI database and software, we converted food items from the questionnaire to quantitative estimates of nutrients. Fluoride content of the diet was not assessed, nor was use of other fluoride-containing products.

A modification of the Tooth Surface Index of Fluorosis (Horowitz et al., 1984) was used for assessment of dental fluorosis. The purpose of the assessment of fluorosis was twofold. First, it provided a method for us to ensure that the participants were exposed to the presumed level of fluoride during the development of their teeth. Fluorosis was also measured for determination of whether the severity of dental fluorosis was associated with bone mass. Because a complete dental examination would have been too time-consuming, only the labial surfaces of the anterior teeth were examined (13-23 and 33-43).

Descriptive statistics for each of the variables were generated by use of the Michigan Interactive Data Analysis System (MIDAS). The association between bone mass and the covariables was assessed via multiple regression analyses with SAS. All associations that could be considered statistically significant $(p \leq 0.05)$ are presented, and no statistical adjustments have been made for multiple comparisons.

\section{Results.}

A total of 151 post-menopausal women age 39-87 years (mean 61, mode 60) completed all aspects of data collection. Sixty-nine were lifelong residents of Deming, and the remaining 82 were lifelong residents of Lordsburg. Non-smokers constituted $76 \%$ of the sample, $70 \%$ did not drink alcoholic beverages, and only $5 \%$ of the sample reported alcohol consumption of ten drinks or more per week. The women tended to be relatively sedentary, with $62 \%$ reporting no regular physical activity or labor. Slightly less than half $(42 \%)$ reported using vitamin or mineral supplements regularly, most commonly multiple vitamins. In terms of total daily calcium intake via both food and vitamin sources, only $5 \%$ consumed at least $800 \mathrm{mg}$ of calcium per day, despite the fact that $20 \%$ were taking supplements containing various levels of calcium.

Table 2 presents basic demographic characteristics stratified by city of residence, used as a proxy for lifelong fluoride exposure. Years of estrogen deficiency were calculated by subtraction of the years of estrogen supplementation from the number of years since menopause. A comparison of the two population groups in terms of the anthropometric measures shows that women in Lordsburg tended to be shorter and heavier than Deming women, thereby leading to a significant difference ( $p$ $=0.010$ ) in the mean Quetelet index, an obesity index defined as (weight)/(height ${ }^{2}$ ) (Revicki and Israel, 1986). The percentage of Deming women taking thiazide diuretics, a medication commonly used for control of hypertension, was significantly greater than for the Lordsburg residents $(p=0.01)$, even though the self-reported prevalence of diagnosed hypertension did not differ between the two communities. The two communities did not differ with regard to any of the other covariables measured, except dental fluorosis score. As would be expected from community water fluoride concentrations, the prevalence of dental fluorosis was significantly higher in Lordsburg, with $97.4 \%$ of the dentate residents having fluorosis, compared with only $22.8 \%$ of the dentate Deming residents $(p<0.001)$. The mean TSIF score for the 77 dentate women in Lordsburg was 4.56 , while the mean TSIF score was 0.35 for the 57 dentate Deming residents $(\mathrm{p}<0.001)$. 

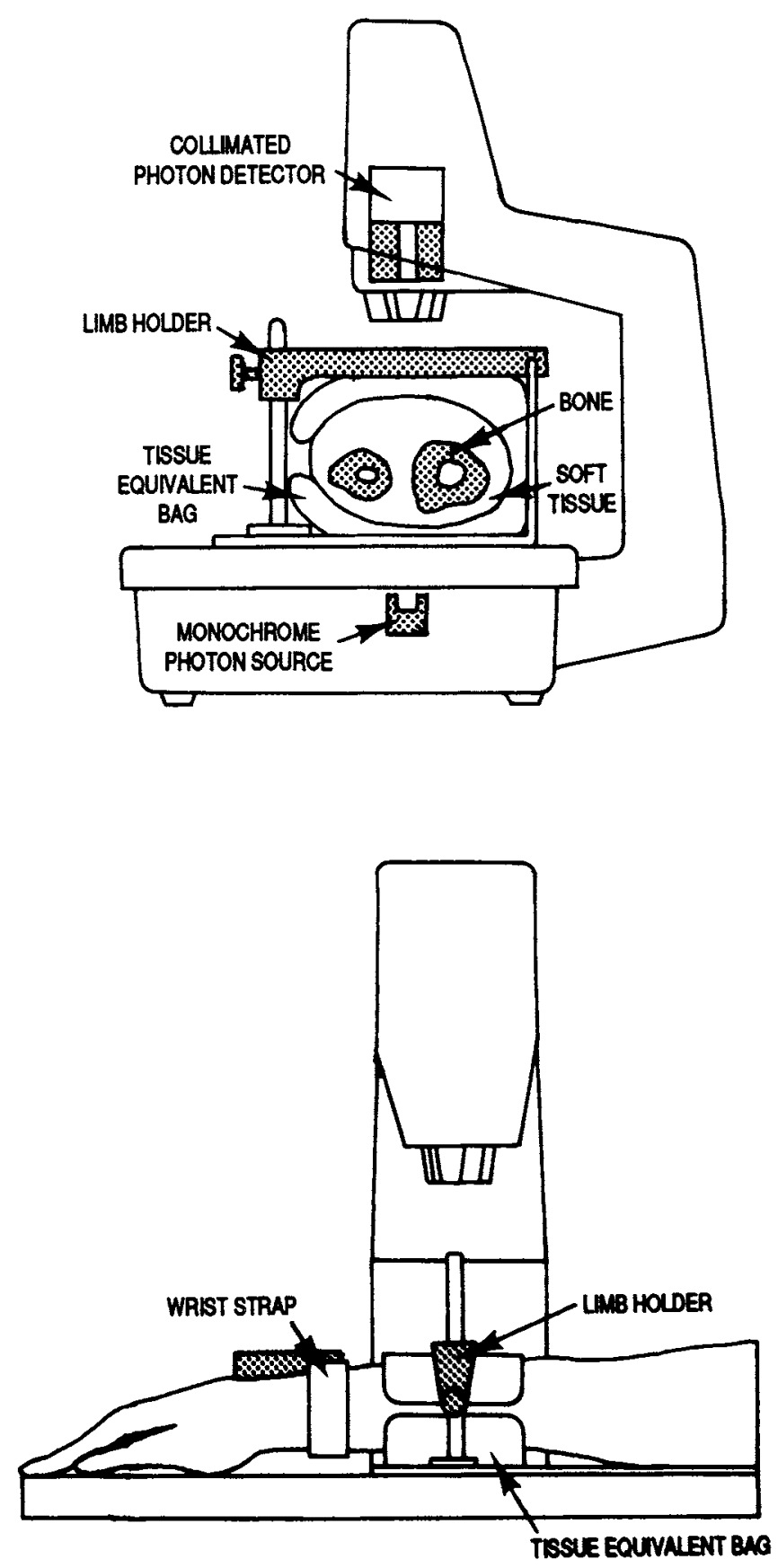

Fig.-Norland Model 2780 Single-Photon Bone Densitometer.

Table 3 presents information regarding the cortical bone measures stratified by city of residence. Based solely on these bivariate analyses, there was no difference in cortical bone mass between the two communities, although there was a tendency toward lower bone mass in Lordsburg.

Because there were significant differences between the two communities in terms of the previously-mentioned covariables, multiple regression analyses (which control for the covariables) were carried out. Based upon an analysis of all possible variable subsets, two models appeared as the "best" predictors of bone mass. The significant predictors of bone mass in Model 1 were weight, years since menopause, city of residence, and the presence of diabetes (Table 4). Although there were significant differences in the ethnic composition of the two com-

munities, ethnic origin did not appear as a significant predictor of bone mass. Model 2 contained the same variables as Model 1 , plus current estrogen supplementation (Table 5). For both of these regression models, a negative parameter estimate for city of residence indicates that living in a community with high levels of water-borne fluoride was associated with decreased bone mass. Based upon the parameter estimates generated in Model 2, and a $95 \%$ confidence interval, post-menopausal women living in the high-fluoride community had a bone mass ranging from 0.004 to $0.039 \mathrm{~g} / \mathrm{cm}^{2}$ less than that of similar women living in the optimal fluoride community. The effect of city of residence can also be expressed as a percentage reduction in bone mass; a Lordsburg woman had approximately $7 \%$ less bone mass than a Deming peer of similar weight and years since menopause. City of residence became a significant predictor of bone mass only after both weight and menopausal status were controlled for, thereby explaining why its significance was not apparent in the descriptive statistics.

\section{Discussion.}

Previous studies in the 1950's and 1960's utilized radiography to measure osteopenia, but a major drawback with radiographs as a measurement technique is that osteopenia is not detectable until approximately $30 \%$ of the bone mass has been lost (Richardson et al., 1985). Single photon absorptiometry, developed subsequent to these earlier studies, is a more sensitive and accurate method for measurement of cortical bone mass (Andresen and Nielsen, 1986). It is also simple to use, readily calibrated, and it exposes the participant to much lower doses of radiation. The computer-generated results also prevent the introduction of bias into investigations that are not "blind" in terms of the exposure of interest.

The negative association we found between fluoride exposure and bone mass was not an anticipated result, since this study was stimulated by the hypothesis that fluoride may actually prevent overall skeletal osteopenia by increasing cortical bone mass. However, we cannot attribute this result to bias or random error, since the other significant findings were consistent with theoretical considerations and prior research. For example, our study confirmed the fact that cortical bone mass and years since menopause are inversely related. The hypothesis that estrogen supplementation and obesity are both protective against osteopenia was also confirmed by this study (Tables 4 and 5).

Despite methodological differences, comparison with earlier studies is still instructive. Based on an evaluation of radiographs, and using only descriptive statistics, Leone et al. (1955) hypothesized that fluoride may be beneficial in preventing osteopenia. To test this hypothesis, Bernstein et al. (1966) used radiographs of the lumbar spine (predominantly trabecular bone) to evaluate the prevalence of osteopenia in a high-fluoride (4.0$5.8 \mathrm{ppm})$ vs. a low-fluoride (0.15-0.30 ppm) area. Based on an interpretation of the radiographs, the authors concluded that older women residing in a high-fluoride area had a lower risk of developing osteopenia.

Although Bernstein et al. (1966) did not control for confounding variables, such as menopausal state, their results did spur researchers to test fluoride as a therapeutic agent in the treatment of osteoporosis (Jowsey et al., 1968). It has been shown that fluoride therapy can actually increase lumbar spine density and increase trabecular bone volume on iliac crest bone biopsies (Eriksen et al. , 1985). The effect of therapeutic doses of fluoride on cortical bone, however, is not as clear. Bone mass measured at sites of predominantly cortical bone showed either no change or small decreases after fluoride therapy 
TABLE 2

DEMOGRAPHIC CHARACTERISTICS STRATIFIED BY CITY OF RESIDENCE FOR THE 151 PARTICIPANTS

\begin{tabular}{lccc}
\hline \hline Variable & Deming & Lordsburg & $\mathrm{p}$ Value \\
\hline Number of Participants & 69 & 82 & Not Applicable \\
Age Range (years) & $48-87$ & $39-81$ & Not Applicable \\
Mean Age (years) & 63.5 & 58.6 & $0.002^{*}$ \\
Percent Hispanic & 57.9 & 81.6 & $<0.001^{* *}$ \\
Weight (kg) & 64.8 & 72.5 & $0.082^{*}$ \\
Height (cm) & 160.6 & 158.4 & $0.020^{*}$ \\
Mean TSIF Score & $0.35(\mathrm{n}=57)$ & $4.56(\mathrm{n}=77)$ & $<0.001^{*}$ \\
Years Since Menopause & 15.87 & 13.68 & $0.225^{*}$ \\
Years Estrogen Deficiency & 12.57 & 12.13 & $0.808^{*}$ \\
\hline
\end{tabular}

${ }^{*} t$ test, ${ }^{* *}$ chi-square.

TABLE 3

CORTICAL BONE MEASURES STRATIFIED BY CITY OF RESIDENCE FOR 151 FEMALE PARTICIPANTS

\begin{tabular}{lccc}
\hline $\begin{array}{c}\text { Deming } \\
\text { Cortical Bone Measure }\end{array}$ & $\begin{array}{c}\text { Lordsburg } \\
\text { Mean } \pm \text { S.D. }\end{array}$ & $\begin{array}{c}\mathrm{p} \text { Value } \\
t \text { test }^{*}\end{array}$ \\
\hline $\begin{array}{llll}\text { Bone Mineral Content } \\
\quad(\mathrm{g} / \mathrm{cm})\end{array}$ & $0.78 \pm 0.19$ & $0.75 \pm 0.19$ & 0.368 \\
Bone Width $(\mathrm{cm})$ & $2.39 \pm 0.23$ & $2.37 \pm 0.17$ & 0.438 \\
Bone Mass (BMC/BW) & $0.32 \pm 0.07$ & $0.32 \pm 0.07$ & 0.480 \\
$\quad\left(\mathrm{~g} / \mathrm{cm}^{2}\right)$ & & & \\
\hline${ }^{*}$ Null Hypothesis: $\mu$ (Deming) $=\mu$ (Lordsburg). \\
\hline
\end{tabular}

(Briancon and Meunier, 1981; Riggs et al., 1980). These findings led Eastell and Riggs (1987) to state that "Some evidence suggests that trabecular bone may increase at the expense of cortical bone during fluoride therapy." If therapeutic doses of fluoride do have a differential effect on cortical and trabecular bone mass, a differential effect may also be noted at lower doses. This could partially explain why Bernstein et al. (1966) noted beneficial effects, while negative effects were indicated in our study. Trabecular bone also has a more active remodeling system than cortical bone and is therefore more sensitive to the effects of fluoride (Parfitt, 1983).

Although several researchers have investigated the relationship between water fluoride content and the incidence of hip fractures (Goggin et al., 1965; Madans et al., 1983; Arnala et al., 1986; Simonen and Laitinen, 1985; Simonen et al., 1984), only one other community-based study has attempted to evaluate the effect of high-fluoride levels in a water supply on cortical bone mass. In this study, conducted by Sowers et al. (1986), bone mass of the distal radius was evaluated via single-photon absorptiometry, and a comparison was made between women residing in a high-fluoride area $(4.0 \mathrm{ppm} \mathrm{F})$ and women living in two optimally fluoridated communities (1.0 ppm F). After adjusting for all known confounding variables, Sowers et al. (1986) found that levels of bone mass in the high-fluoride community were approximately $2 \%$ lower than those found in the optimally fluoridated communities, a difference that did not achieve statistical significance. The inability to show statistical significance may have been associated with the relatively short exposure time necessary to qualify for the study (five years). Given that the older population group studied ranged in age from 55 to 80 years, five years of fluoride exposure may have had little impact on cortical bone mass.

It must be remembered that both our study, and that conducted by Sowers et al. (1986), compared a high-fluoride (3.5$4.0 \mathrm{ppm}$ ) with an optimal-fluoride community. No low-fluoride community was included in either study. Although the relationship between water fluoride content and bone fluoride content has been described as a straight-line function (Zipkin et al., 1958), the relationship between water fluoride content
TABLE 4

MODEL 1-PARAMETER ESTIMATES, STANDARD ERRORS, AND $p$ VALUES FOR PREDICTION OF BONE MASS

\begin{tabular}{lrcc}
\hline Variable & $\begin{array}{c}\text { Parameter } \\
\text { Estimate }\end{array}$ & $\begin{array}{c}\text { Standard } \\
\text { Error }\end{array}$ & $\begin{array}{c}\text { Probability }>|\mathrm{T}| \\
\text { Null Hypothesis: } \beta=0\end{array}$ \\
\hline Intercept & 0.2301 & 0.0225 & $<0.001$ \\
Weight & 0.0018 & 0.0003 & $<0.001$ \\
Years Since Menopause & -0.0025 & 0.0004 & $<0.001$ \\
City of Residence (F-) & -0.0230 & 0.0088 & 0.010 \\
Presence of Diabetes & 0.0286 & 0.0138 & 0.040 \\
\hline
\end{tabular}

${ }^{*}$ Coding for city of residence: Deming (optimal-fluoride) $=0$, Lordsburg (high-fluoride) $=1$.

Null Hypothesis: all $\beta \mathrm{s}=0, F=27.670, \mathrm{p}<0.001, \mathrm{r}^{2}=0.435$.

TABLE 5

MODEL 2-PARAMETER ESTIMATES, STANDARD ERRORS, AND $\mathrm{p}$ VALUES FOR PREDICTION OF BONE MASS

\begin{tabular}{lrcc}
\hline Variable & $\begin{array}{c}\text { Parameter } \\
\text { Estimate }\end{array}$ & $\begin{array}{c}\text { Standard } \\
\text { Error }\end{array}$ & $\begin{array}{c}\text { Probability }>|T| \\
\text { Null Hypothesis: } \beta=0\end{array}$ \\
\hline Intercept & 0.2198 & 0.0225 & $<0.001$ \\
Weight & 0.0019 & 0.0003 & $<0.001$ \\
Years Since Menopause & -0.0025 & 0.0004 & $<0.001$ \\
City of Residence (F - ) & -0.0215 & 0.0087 & 0.014 \\
Estrogen Supplements & 0.0314 & 0.0121 & 0.010 \\
Presence of Diabetes & 0.0294 & 0.0135 & 0.032 \\
\hline
\end{tabular}

${ }^{*}$ Coding for city of residence: Deming (optimal-fluoride) $=0$, Lordsburg (high-fluoride) $=1$.

Null Hypothesis: all $\beta s=0, F=24.387, p<0.001, r^{2}=0.460$.

and cortical bone mass may not be linear. Instead of having bone mass continually increase with water fluoride content, there may be a threshold level above which increased fluoride may in fact be detrimental to cortical bone mass. This theory was postulated by Simonen et al. (1984), who stated that "... (the) optimal fluoride intake (for the prevention of hip fractures) is relatively narrow ...". The results of the study conducted by Simonen et al. (1984) indicated that the optimal fluoride concentration for the prevention of hip fractures among women is from 1.5 to $2.5 \mathrm{ppm}$ F. For determination of whether a threshold level does exist, research must be conducted which evaluates the bone mass of individuals exposed to a wide array of fluoride levels ranging from negligible to moderately high.

Although the results of this study neither support nor refute the public policy of community water fluoridation, they may support the standards for fluoride levels set by the Environmental Protection Agency (EPA). Effective October 1, 1987, the EPA set the maximum allowable concentration of fluoride at $4.0 \mathrm{ppm} \mathrm{F}$, while suggesting that no more than $2.0 \mathrm{ppm} F$ should be the goal for community water systems. Although definitive health hazards have never been causally associated with the ingestion of levels up to $4.0 \mathrm{ppm} \mathrm{F}$, the results of this study suggest that a negative health outcome (apart from unsightly dental fluorosis) may in fact be associated with lifelong ingestion of water with five times the recommended fluoride levels. Our results suggest that prospective studies-based in communities with high, recommended, and low fluoride concentrations in water-would help define the appropriateness of the EPA guidelines with respect to bone mass in the growing elderly population.

\section{REFERENCES}

ANDRESEN, J, and NIELSEN, H.E. (1986): Assessment of Bone Mineral Content and Bone Mass by Non-invasive Radiologic Methods, Acta Radiol 27:609-617.

ANSELL, B.M. and LAWRENCE, J.S. (1966): Fluoridation and the 
Rheumatic Diseases. A Comparison of Rheumatism in Watford and Leigh, Ann Rheum Dis 25:67-75.

ARNALA, I.; ALHAVA, E.M.; KIVIVOURI, R.; and KAURANEN, P. (1986): Hip Fracture Incidence not Affected by Fluoridation. Osteofluorosis Studied in Finland, Acta Orthop Scand $57: 344-348$

AVORN, J. and NIESSEN, L.C. (1986): Relationship Between Long Bone Fracturcs and Water Fluoridation, Gerodontics 2:175-179.

BERNSTEIN, D.S.; SADOWSKY, N.; HEGSTED, D.M.; GURI, D.; and STARE, F.J. (1966): Prevalence of Osteoporosis in Highand Low-fluoride Areas in North Dakota, J Am Med Assoc 198:499504.

BRIANCON, D. and MEUNIER, P.J. (1981): Treatment of Osteoporosis with Fluoride, Calcium and Vitamin D, Orthop Clin North Am 12:629-648.

DEAN, H.T. (1933): Distribution of Mottled Enamel in the United States, Public Health Rep 48:703-734.

EASTELL, R. and RIGGS, B.L. (1987): Treatment of Osteoporosis, Obstet Gynecol Clin North Am 14:77-88.

ERIKSEN, E.F.; MOSEKILDE, L.; and MELSEN, F. (1985): Effect of Sodium Fluoride, Calcium, Phosphate and Vitamin $\mathrm{D}_{2}$ on Trabecular Bone Balance and Remodeling in Osteoporotics, Bone $6: 381-389$.

GOGGIN, J.E.; HADDON, W.; HAMBLY, G.S.; and HOVELAND, J.R. (1965): Incidence of Femoral Fractures in Postmenopausal Women. Before and After Water Fluoridation, Public Health Rep 80:1005-1012.

HOROWITZ, H.S.; DRISCOLL, W.S.; MEYERS, R.J.; HEIFETZ, S.B.; and KINGMAN, A. (1984): A New Method for Assessing the Prevalence of Dental Fluorosis-The Tooth Surface Index of Fluorosis, $J$ Am Dent Assoc 109:37-41.

JOWSEY, J.; SCHENK, R.K.; and REUTTER, F.W. (1968): Some Results of the Effect of Fluoride on Bone Tissue in Osteoporosis, $J$ Clin Endocrinol Metab 28:869-874.

LEONE, N.C.; STEVENSON, C.A.; HILBISH, T.F.; and SOSMAN, M.C. (1955): A Roentgenologic Study of a Human Population Exposed to High-fluoride Domestic Water (a 10-year study). Am $J$ Roentg 74:874-885.

LIAN, Z.C. and WU, E.H. (1986): Osteoporosis-an Early Radiographic Sign of Endemic Fluorosis, Skeletal Radiol 15:350-353.

MADANS, J.; KLEINMAN, J.C.; and CORONI-HUNTLEY, J.
(1983): The Relationship Between Hip Fracture and Water Fluoridation: an Analysis of National Data, Am J Public Health 73:296298.

PARFITT, A.M. (1983): The Physiologic and Clinical Significance of Bone Histomorphometric Data. In: Bone Histomorphometry: Techniques and Interpretation, R. Recker, Ed., Boca Raton, FL: CRC Press, pp. 143-223.

REVICKI, D.A. and ISRAEL, R.G. (1986): Relationship Between Body Mass Indices and Measures of Body Adiposity, Am J Public Health 76:992-994.

RICHARDSON, M.L.; GENANT, H.K.; CANN, C.E.; ETTINGER, B.; GORDAN, G.S.; KOLB, F.O.; and REISER, U.J. (1985): Assessment of Metabolic Bone Disease by Quantitative Computed Tomography, Clin Orthop 195:224-238.

RIGGS, B.L.; HODGSON, S.F.; HOFFMAN, D.L.; KELLY, P.J.; JOHNSON, K.A.; and TAVES, D. (1980): Treatment of Primary Osteoporosis with Fluoride and Calcium. Clinical Tolerance and Fracture Occurrence, $J$ Am Med Assoc 243:446-449.

SIMONEN, O.; KNEKT, P.; and LAITINEN, O. (1984): Fluoride in Drinking Water and Osteoporosis, Duodecim 100:342-350.

SIMONEN, O. and LAITINEN, O. (1985): Does Fluoridation of Drinking-Water Prevent Bone Fragility and Osteoporosis?, Lancet 2:432-434.

SOWERS, M.R.; WALLACE, R.B.; and LEMKE, J.H. (1986): The Relationship of Bone Mass and Fracture History to Fluoride and Calcium Intake: a Study of Three Communities, Am J Clin Nutr 44:889-898.

STRIFFLER, D.F. (1955): Fluoridation in New Mexico: its Present Status, NM State Dent $J$ 5:3-11.

US DEPARTMENT OF COMMERCE (1980): Population Characteristics. New Mexico. Washington, DC: Bureau of the Census.

US PUBLIC HEALTH SERVICE (1959): Natural Fluoride Content of Communal Water Supplies, Bethesda, MD: National Institutes of Health.

US PUBLIC HEALTH SERVICE (1969): Natural Fluoride Content of Communal Water Supplies, Bethesda, MD: National Institutes of Health.

ZIPKIN, I.; MCCLURE, F.J.; LEONE, N.C.; and LEE, W.A. (1958): Fluoride Deposition in Human Bones after Prolonged Ingestion of Fluoride in Drinking Water, Public Health Rep 73:732-740. 